\title{
A QM/MM Study of Nitrite Binding Modes in a Three-Domain Heme-Cu Nitrite Reductase
}

\author{
Kakali Sen ${ }^{1,2} \oplus$, Michael A. Hough ${ }^{1} \oplus$, Richard W. Strange ${ }^{1} \oplus$, Chin W. Yong ${ }^{2}$ and \\ Thomas W. Keal ${ }^{2, *(D)}$ \\ 1 School of Biological Sciences, University of Essex, Wivenhoe Park, Colchester, Essex CO4 3SQ, UK; \\ kakali.sen@stfc.ac.uk (K.S.); mahough@essex.ac.uk (M.A.H.); rstrange@essex.ac.uk (R.W.S.) \\ 2 Scientific Computing Department, STFC Daresbury Laboratory, Warrington, Cheshire WA4 4AD, UK; \\ chin.yong@stfc.ac.uk \\ * Correspondence: thomas.keal@stfc.ac.uk; Tel.: +44-1925603849 \\ Academic Editor: Hai Lin
}

This paper is published as part of a thematic issue of Molecules on "Combined Quantum Mechanical and Molecular Mechanical Methods and Simulations". (http:/ / www.mdpi.com/journal/molecules/special_issues/QM)

\begin{abstract}
Copper-containing nitrite reductases (CuNiRs) play a key role in the global nitrogen cycle by reducing nitrite $\left(\mathrm{NO}_{2}{ }^{-}\right)$to nitric oxide, a reaction that involves one electron and two protons. In typical two-domain CuNiRs, the electron is acquired from an external electron-donating partner. The recently characterised Rastonia picketti ( $p p N i R)$ system is a three-domain CuNiR, where the cupredoxin domain is tethered to a heme $c$ domain that can function as the electron donor. The nitrite reduction starts with the binding of $\mathrm{NO}_{2}{ }^{-}$to the $\mathrm{T} 2 \mathrm{Cu}$ centre, but very little is known about how $\mathrm{NO}_{2}{ }^{-}$binds to native $\mathrm{RpNiR}$. A recent crystallographic study of an $R p \mathrm{NiR}$ mutant suggests that $\mathrm{NO}_{2}{ }^{-}$may bind via nitrogen rather than through the bidentate oxygen mode typically observed in two-domain CuNiRs. In this work we have used combined quantum mechanical/molecular mechanical (QM/MM) methods to model the binding mode of $\mathrm{NO}_{2}{ }^{-}$with native $R p \mathrm{NiR}$ in order to determine whether the $\mathrm{N}$-bound or O-bound orientation is preferred. Our results indicate that binding via nitrogen or oxygen is possible for the oxidised $\mathrm{Cu}$ (II) state of the $\mathrm{T} 2 \mathrm{Cu}$ centre, but in the reduced $\mathrm{Cu}(\mathrm{I})$ state the $\mathrm{N}$-binding mode is energetically preferred.
\end{abstract}

Keywords: nitrite reductases; three-domain CuNiRs; RpNiR; nitrite binding; QM/MM methods

\section{Introduction}

Microbial copper-containing nitrite reductases (CuNiRs) are enzymes that catalyse the reduction of $\mathrm{NO}_{2}{ }^{-}$to $\mathrm{NO}$, a key denitrification step in the global nitrogen cycle [1]. The most studied and well-characterized are the two-domain $\mathrm{CuNiRs,} \mathrm{which} \mathrm{are} \mathrm{homotrimeric} \mathrm{proteins} \mathrm{with} \mathrm{each} \mathrm{monomer}$ consisting of two cupredoxin-like domains containing an electron-transfer type $1 \mathrm{Cu}(\mathrm{T} 1 \mathrm{Cu})$ site and a catalytic type $2 \mathrm{Cu}(\mathrm{T} 2 \mathrm{Cu})$ site [2,3]. The T1Cu is typically coordinated with Cys-Met-His 2 and the $\mathrm{T} 2 \mathrm{Cu}$ is coordinated with $\mathrm{His}_{3}-\mathrm{H}_{2} \mathrm{O}$ in the resting phase. The two sites are separated by approx. $12.5 \AA$ and are connected by a Cys-His bridge, with Cys coordination to the T1Cu and His to the T2Cu. Catalytic reduction occurs at the $\mathrm{T} 2 \mathrm{Cu}$ site after binding of $\mathrm{NO}_{2}{ }^{-}$via replacement of the bound water and involves a proton-coupled electron transfer reaction: $\mathrm{NO}_{2}{ }^{-}+2 \mathrm{H}^{+}+\mathrm{e}^{-} \rightarrow \mathrm{NO}+\mathrm{H}_{2} \mathrm{O}$. The electron is internally transferred from the $\mathrm{T} 1 \mathrm{Cu}$ site to the $\mathrm{T} 2 \mathrm{Cu}$ site via the Cys-His bridge and the $\mathrm{T} 1 \mathrm{Cu}$ in 
turn receives an electron from external redox proteins such as azurins and pseudoazurins or c-type cytochromes [2].

In recent years, two new sub-classes of $\mathrm{CuNiRs}$ have been identified that, in addition to the core two-domain structure, have a cupredoxin or heme $c$ domain fused to the $\mathrm{N}$ - or C-terminus respectively [4-7]. Genomic analysis revealed a wide distribution of this novel type of CuNiR in several organisms [8]. The first three-domain $\mathrm{CuNiR}$ with a cytochrome $c$ domain fused to the core two-domain cupredoxin to be biochemically characterized was isolated from Rastonia picketti (RpNiR) with its structure determined to $1.01 \AA$ resolution [7,9]. The structure reveals it to be trimeric with high structural similarity to the cupredoxin domain in two-domain CuNiRs such as AcNiR (Figure 1a,b). The heme $c$ domain of one monomer is in close proximity to the $\mathrm{T} 1 \mathrm{Cu}$ site from another monomer, with the heme Fe ion and T1Cu unit within $10.4 \AA$ of each other, an acceptable electron transfer distance (Figure 2 in [9]), and hence the heme $c$ is capable of supplying electrons to T1Cu during turnover.

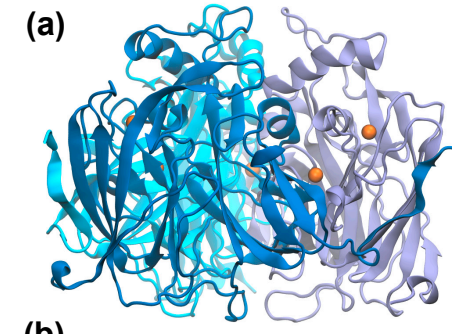

(b)

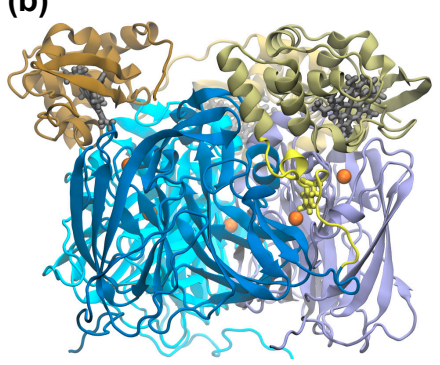

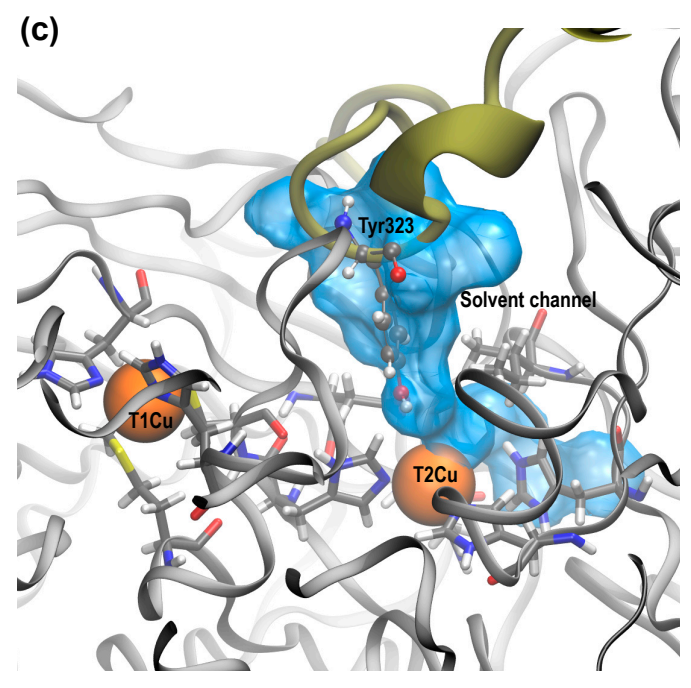

Figure 1. Structural similarities in two domain Achromobacter cycloclastes $\mathrm{CuNiR}(A c \mathrm{NiR})$ and three domain RpNiR: (a) Structure of $A c N i R$, PDB ID: 2BW4. (b) Structure of RpNiR, PDB ID: 3ZIY. The T1 and T2 $\mathrm{Cu}$ ions are represented as orange spheres. The heme $c$ units of the cytochrome domain in $R p N i R$ are shown in grey. The linker chain that tethers the cupredoxin domain and the cytochrome domain is shown in yellow along with Tyr323 which is strategically positioned in the solvent/ligand accessible channel. (c) Structures of $R p \mathrm{NiR}$ and $A c \mathrm{NiR}$ are overlapped and zoomed in at the T2Cu site. The backbone and active site residues from $A c N i R$ are shown. The critical position of Tyr323 in $R p N i R$ blocks the otherwise solvent/ligand accessible channel (shown in blue) in the two-domain CuNiRs. The heme $c$ domain linker from $R p N i R$ that strategically positions Tyr323 is shown in green.

There is a striking similarity between the core cupredoxin domain of $R p N i R$ and the two-domain $A c \mathrm{NiR}$ (Figure 1a,b). However, the additional heme domain necessitates certain rearrangements in the core structure. In two-domain $\mathrm{CuNiRs}, \mathrm{X}$-ray studies revealed the presence of two solvent access channels with the potential to deliver protons from the bulk solvent to the $\mathrm{T} 2 \mathrm{Cu}$ site during the reduction of $\mathrm{NO}_{2}{ }^{-}$, one of which also functions as the substrate access channel $[10,11]$. Structural, spectroscopic and computational studies have revealed the importance of the substrate access channel in controlling the hydration of the active site [12-14], the orientation of the nitrite and selectivity for small ligands [15,16], and determining the rate of turnover [12]. In $R p N i R$, the linker that tethers the heme $c$ domain to the cupredoxin domain is poised in such a way that the sidechain of one of its residues, Tyr323, resides close to the T2Cu site, thereby blocking this substrate channel (Figure 1c). The position of the Tyr323 is critical and it is hypothesized to have mechanistic implications. Unusually, the three-domain $R p N i R$ has a remarkably low affinity for binding $\mathrm{NO}_{2}{ }^{-}$in the oxidized T2Cu state [7]. 
Another striking similarity among all CuNiRs is the presence of conserved Asp and His residues in the $\mathrm{T} 2 \mathrm{Cu}$ active site, which are believed to participate in the proton transfer that is necessary for reduction [16-19]. In $R p N i R$ the corresponding Asp and His are Asp97 and His240, respectively. A mutant of $R p \mathrm{NiR}$ in which the catalytically important Asp97 was mutated to Asn (D97N) [20] revealed that binding of $\mathrm{NO}_{2}{ }^{-}$was possible after soaking the NO-bound mutant with sodium nitrite, where $\mathrm{NO}$ is replaced by $\mathrm{NO}_{2}{ }^{-}$. The D97N NO-bound structure revealed a displacement of Tyr323 from the substrate access channel, associated with adjustment of the linker loop (Ser315-Ser321), thereby opening up the substrate access channel and allowing $\mathrm{NO}_{2}{ }^{-}$to bind. In this mutant, $\mathrm{NO}_{2}{ }^{-}$is bound via the nitrogen atom rather than the bidentate $\eta^{2-} \mathrm{O}, \mathrm{O}$ ('top-hat') mode observed in the crystal structures of several two-domain CuNiRs [10,21-23].

The focus of this work is on modelling the $\mathrm{NO}_{2}{ }^{-}$binding mode at the $\mathrm{T} 2 \mathrm{Cu}$ site in native $\mathrm{RpNiR}$, following ligand entry into the active site region. The $K_{\mathrm{m}}$ of $R p \mathrm{NiR}$ for nitrite is similar to that of other two-domain CuNiRs in which the nitrite ion is observed in crystal structures to bind in a bidentate 'top-hat' orientation. The recent development of Multiple Structures from One Crystal (MSOX) methodology has led to the creation of structural movies of $\mathrm{NO}_{2}{ }^{-}$reduction at the $\mathrm{T} 2 \mathrm{Cu}$ site in the two-domain $A c \mathrm{NiR}$ [21]. One of the features was the change of $\mathrm{NO}_{2}{ }^{-}$binding mode from top hat to a 'side-on' orientation where both the oxygen and nitrogen atoms are equidistant from $\mathrm{T} 2 \mathrm{Cu}$ (Figure $2 \mathrm{in}$ [21]), which is thought to occur as a result of reduction of the T2Cu. In addition, the mode of nitrite binding is important for mechanistic understanding of the reduction of nitrite in two-domain CuNiRs, which may proceed according to either an ordered [24-26] or random-sequential mechanism $[27,28]$ and there is similar speculation about the mechanism in three-domain $R p N i R[7,20]$. As binding via either $\mathrm{O}$ or $\mathrm{N}$ is possible for the nitrite ligand, it is essential to identify the initial binding mode of nitrite in the active site to elucidate the mechanism for $R p N i R$. Until now no direct structural information of the binding mode of $\mathrm{NO}_{2}{ }^{-}$in native $\mathrm{R} p \mathrm{NiR}$ is available, although binding via nitrogen was observed for the D97N mutant [20]. We have therefore used combined quantum mechanical and molecular mechanical (QM/MM) methods to determine whether binding of $\mathrm{NO}_{2}{ }^{-}$occurs via the $\mathrm{N}$ or O-atom in native $\mathrm{RpNiR}$ and have compared the calculated structures to the available experimental data for the D97N mutant as well as the available structural data on two-domain CuNiRs.

\section{Results}

\subsection{Molecular Dynamics of Native and D97N RpNiR in the Resting State}

Initial classical MD simulations were carried out to investigate the positioning of the crucial active site residues such as Tyr323 and provide snapshots for subsequent QM/MM calculations. Analogously to other CuNiRs, the conserved active site Asp residue, Asp97 in $R p N i R$ is likely a key player for the proton transfer required during catalytic reduction at the $\mathrm{T} 2 \mathrm{Cu}$. We therefore ran simulations of the resting states of three $R p N i R$ trimer systems: the two protonation states of Asp97 (which we label "D97" and "D97p" for the unprotonated and protonated states respectively) and an in silico mutated structure "D97N" where Asp97 is replaced with Asn. Conformational variations within the T2Cu active sites of the three independent subunits (chains A, B and C) of the trimer were analysed over the unrestrained last $75 \mathrm{~ns}$ of a total of $80 \mathrm{~ns}$ of MD trajectories for each of these three systems (see the methodology section for further details).

As the Tyr323 residue sits in the substrate access channel it interacts with the hydration network connecting Asp97, T2Cu and His240. Figure 2a depicts the dynamic hydrogen bond distance between the phenolic $\mathrm{H}$ atom of Tyr323 and the nearest O atom of Asp97/nearest N- or O-atom of Asn97. In the case of D97, a strong hydrogen bond is present between the negatively charged carboxylic acid group of Asp97 and Tyr323. Protonation of Asp97 weakens this interaction and as a result a transient break in this interaction is frequently observed in the D97p system. A similar situation is observed for the D97N mutant with the transient breaks becoming more frequent. Interestingly, there is a complete breaking of the TyrO-H $\cdots$ O-Asp97 interaction at $\sim 69 \mathrm{~ns}$ in one subunit of the D97 
system (chain A in Figure 2a). This is due to movement of the Tyr323 away from the T2Cu pocket (vide infra). To understand the relative position of these two amino acids with respect to the T2Cu ion, the time evolution of the distances between the T2Cu and the centre of mass (COM) of the side chains of Tyr323 and Asp97 during MD were measured and are plotted in Figure 2b, while the averaged values over the entire trajectory for each subunit are given in Table 1 . The average distances between Asp97 and T2Cu are similar to those in the crystal structure. The average distance of Asn97-T2Cu for the mutant D97N simulations is larger than that measured in the recent D97N crystal structure [20] $(4.30 \AA)$. The other distance, T2Cu and COM of the Tyr323 side chain, in the native crystal geometry is $7.16 \AA$. The average values for the T2Cu-Tyr323 distance in D97, D97p and D97N systems also agree well with the crystal structure (Table 1).

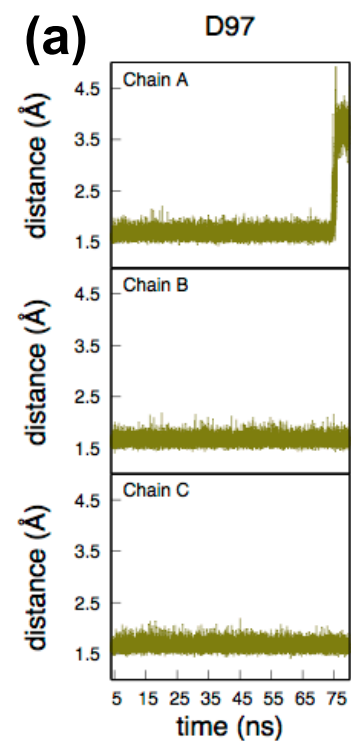

(b)

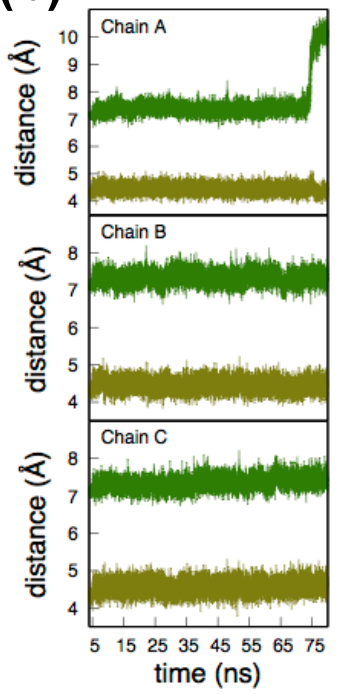

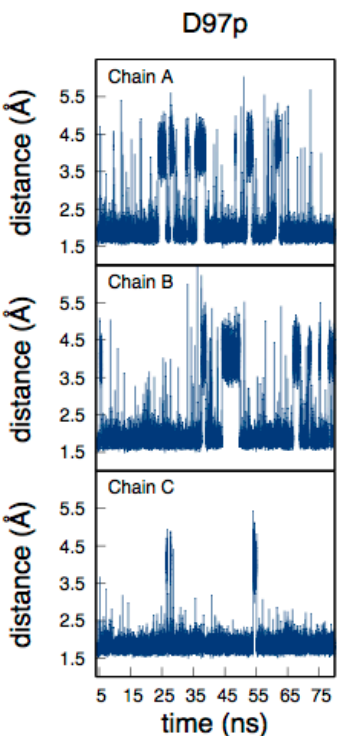

D97p

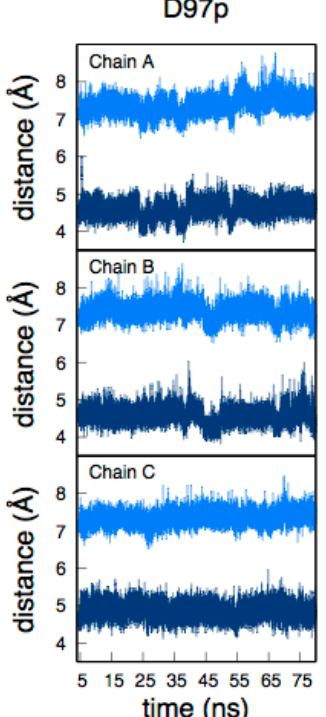

$\mathrm{D} 97 \mathrm{~N}$

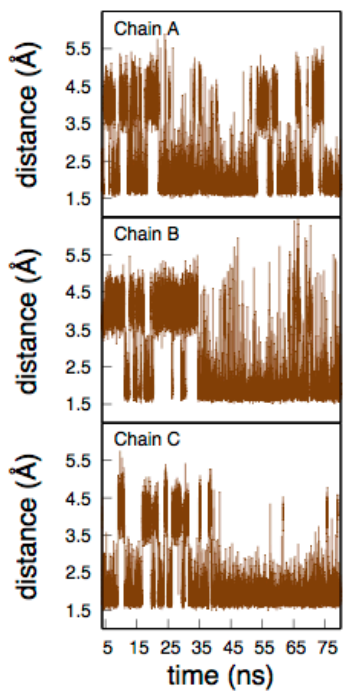

D97N

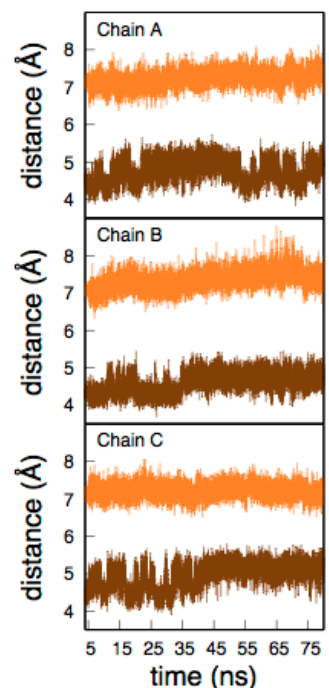

Figure 2. Relevant distances from $75 \mathrm{~ns}$ of MD trajectories for the three independent subunits (chains A, $\mathrm{B}$ and C) of $R p \mathrm{NiR}$, simulating deprotonated (D97) and protonated (D97p) active site Asp97 and the Asn97 mutant (D97N). (a) The distance between Tyr323-phenolic H to the nearest O of Asp97 (for D97 and D97p) and to O/N- of Asn97 (for D97N). (b) The distance between (i) the T2Cu ion and the centre of mass of the side chain of Asp97 (olive in left panel and dark blue in middle panel) and that of Asn97 (brown in right panel); (ii) the T2Cu ion and the centre of mass of the side chain of Tyr323 (green in left panel, light blue in middle panel and orange in right panel). 
Table 1. Average distances between the T2Cu ion and the centres of mass of Asp/Asn97 and Tyr323 sidechains during $75 \mathrm{~ns}$ of unconstrained MD simulation. The equivalent crystal structure values are provided for comparison. Distances are in $\AA$.

\begin{tabular}{cccccc}
\hline & & D97 & D97p & D97N & Crystal \\
\hline \multirow{3}{*}{ Asp97/Asn97-Cu } & Chain A & $4.45 \pm 0.18$ & $4.61 \pm 0.23$ & $4.76 \pm 0.32$ & \\
& Chain B & $4.46 \pm 0.18$ & $4.58 \pm 0.24$ & $4.60 \pm 0.29$ & $4.48{\text { (D97) [4.30 }{ }^{\mathrm{a}}}$ \\
& Chain C & $4.57 \pm 0.19$ & $4.88 \pm 0.23$ & $4.96 \pm 0.34$ & \\
\hline \multirow{2}{*}{ Tyr323-Cu } & Chain A & $7.37 \pm 0.19$ & $7.38 \pm 0.24$ & $7.22 \pm 0.22$ & \\
& Chain B & $7.83 \pm 0.49 \mathrm{~b}$ & & \\
& Chain C & $7.35 \pm 0.18$ & $7.38 \pm 0.23$ & $7.35 \pm 0.26$ & 7.16 [9.83 $^{\mathrm{a}}$ \\
& & &
\end{tabular}

${ }^{a}$ From crystal structure of $\mathrm{NO}_{2}{ }^{-}$bound D97N (PDB ID: 5OBO). ${ }^{\mathrm{b}}$ Distance calculated following displacement of Tyr323 in chain A of D97 at $\sim 69$ ns in the MD trajectory.

The exception, as noted above, is in one subunit of D97 (chain A in Figure $2 b$ and Table 1 ) where the Tyr323 becomes displaced from the T2Cu site by $2.5-3.0 \AA$ after $\sim 69 \mathrm{~ns}$. Since the relative positions of Asp97 and T2Cu are unchanged in the same MD timeframe, this implies that it is the flexibility of the linker chain that enables displacement of the Tyr323. Although the orientations of the Tyr323 sidechain in the two cases are different, the displacement seen by MD corroborates the flexibility observed in the D97N crystal structure (Figure S1), where the sidechain is rotated $\sim 90^{\circ}$ away from its position in the native crystal structure (Figure 2a in [20]).

In the D97p and the D97N systems (Figure 2a, middle and right panels) the local H-bond network between Tyr323 and Asp/Asn97 is frequently disrupted. However, within the timescale of measurement Tyr323 remains 'locked' in its position in the substrate channel and so would sterically hinder the entry of $\mathrm{NO}_{2}{ }^{-}$. In the D97 system Tyr323 is held strongly in H-bond interaction by the negatively charged Asp97 but in the case of chain A the Tyr323 nevertheless breaks away towards the end of the simulation (Figure 2b, left panel), becoming displaced in the channel by 2.5-3.0 $\AA$ from its original position relative to the $\mathrm{T} 2 \mathrm{Cu}$ (Figure S1). The distance of Tyr323 from T2Cu in chain A (Table 1) at $\sim 69 \mathrm{~ns}$ is similar to that found by Dong et al. in the crystal structure of NO- and nitrite-bound D97N $\mathrm{RpNiR}$ [20].

\section{2. $\mathrm{QM} / \mathrm{MM}$ Optimization of $\mathrm{NO}_{2}{ }^{-}$Bound Structures}

Snapshots of structures from the MD simulations were taken as the basis for studying the binding mode of nitrite to the T2Cu site. The snapshots were selected to be representative of the conformational variations observed in the MD trajectories described in the previous section, taking them from $25 \mathrm{~ns}$ onwards to ensure that the systems were completely equilibrated after removal of backbone constraints. The nitrite ion was added to the systems as described in the methodology section. QM/MM optimizations were carried out for both the $\mathrm{Cu}$ (II) and $\mathrm{Cu}(\mathrm{I})$ states of the $\mathrm{T} 2 \mathrm{Cu}$ ion, starting from both 'top-hat' and 'N-bound' orientations of $\mathrm{NO}_{2}{ }^{-}$. For each optimisation, the geometry and relative energy of the relaxed structure were assessed.

We categorised the relaxed geometries of the T2Cu site in two ways. First, by the overall geometry of the T2Cu-nitrite complex, which can be either tetragonal or trigonal. This was determined by measuring the twisting angle $\varphi$ between two planes: one defined by $\mathrm{N}\left(\mathrm{NO}_{2}{ }^{-}\right)-\mathrm{T} 2 \mathrm{Cu}-\mathrm{N}(\mathrm{His} 1)$ and the other defined by $\mathrm{N}(\mathrm{His} 2)-\mathrm{T} 2 \mathrm{Cu}-\mathrm{N}$ (His3), following the procedure used by Ryde et al. for blue and green $\mathrm{Cu}$ proteins $[29,30]$. His1 is the axial ligand, defined as the ligand with the largest $\mathrm{N}\left(\mathrm{NO}_{2}{ }^{-}\right)-\mathrm{T} 2 \mathrm{Cu}-\mathrm{N}$ (His) angle, with His2 and His3 the remaining equatorial ligands. For a tetragonal structure $\varphi$ will be approximately $0^{\circ}$ or $180^{\circ}$, while for trigonal structures $\varphi$ will be approximately $90^{\circ}$.

The second assessment was of the orientation of the $\mathrm{NO}_{2}{ }^{-}$ion bound to the $\mathrm{T} 2 \mathrm{Cu}$ centre. The nitrite orientation can be classified as symmetrical N-bound, L-shaped, bidentate top-hat, monodentate top-hat, or side-on. To assign these labels we define a coordinate system in which the centre of mass of $\mathrm{NO}_{2}{ }^{-}$is placed at the origin with the nitrogen atom aligned along the positive $\mathrm{X}$-axis, 
and the oxygen atoms lie on the XY plane, as shown in Figure 3. Two angular measurements describing the position of $\mathrm{Cu}$ in relation to this coordinate system can then be used to classify the different orientations. We define an altitudinal angle $\theta$ as the angle between the projection of $\mathrm{Cu}$ onto the $\mathrm{XZ}$ plane and the $\mathrm{X}$-axis. This angle can be thought of as the 'pitch' of the $\mathrm{NO}_{2}{ }^{-}$ion and describes a change in its orientation from $\mathrm{N}$-bound $\left(0^{\circ}\right)$ to side-on $\left(90^{\circ}\right)$ to top-hat $\left(180^{\circ}\right)$. We also define an azimuthal angle $\psi$ as the angle between the projection of $\mathrm{Cu}$ onto the $\mathrm{XY}$ plane and the $\mathrm{X}$-axis. This angle can be thought of as the ' $\mathrm{yaw}^{\prime}$ of the $\mathrm{NO}_{2}{ }^{-}$ion which circles from N-bound $\left(0^{\circ}\right)$ to L-shaped $\left(\sim 30^{\circ}\right)$ to perpendicular $\left(90^{\circ}\right.$, not observed in practice) to monodentate top-hat $\left(\sim 150^{\circ}\right)$ to bidentate top-hat $\left(180^{\circ}\right)$. The thresholds we use for labelling the nitrite ion orientation in each structure are shown in Table 2.

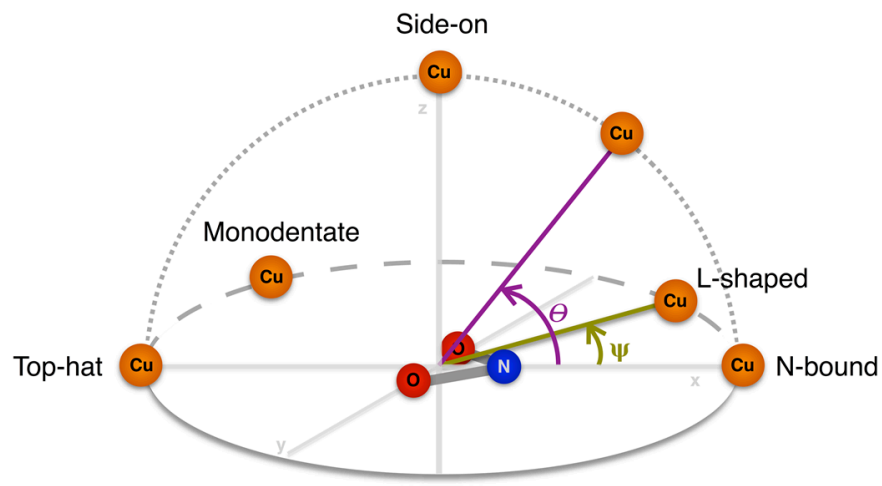

Figure 3. Schematic representation of the geometric angles $\theta$ and $\psi$ that define the orientation of $\mathrm{NO}_{2}{ }^{-}$ bound to $\mathrm{T} 2 \mathrm{Cu}$.

Table 2. Angular thresholds for the characterisation of nitrite binding orientations.

\begin{tabular}{cccc}
\hline Altitudinal Geometry & $\theta$ & Azimuthal Geometry & $\boldsymbol{\Psi}$ \\
\hline N-bound & $0-20^{\circ}$ & $\begin{array}{c}\text { L-shaped } \\
\text { Symmetrical }\end{array}$ & $\begin{array}{c}10-30^{\circ} \\
0-10^{\circ}\end{array}$ \\
\hline \multirow{2}{*}{ Top-Hat } & $160-180^{\circ}$ & Bidentate & $170-180^{\circ}$ \\
& $70-110^{\circ}$ & Monodentate & $140-170^{\circ}$ \\
\hline Side-on & $\mathrm{n} / \mathrm{a}$ \\
\hline
\end{tabular}

The energies of the relaxed conformers were assessed to determine whether there was any preference for one binding mode over another. Absolute energies between the conformers cannot be compared since the total number of atoms of the conformers is not conserved as they are taken from random time steps and a shell of solvent is used. Instead a relative energy was calculated from the difference in energy between relaxed top-hat and $N$-bound structures $\left(\Delta E=E_{\text {top-hat }}-E_{N-b o u n d}\right)$ such that a positive $\Delta \mathrm{E}$ indicates that $\mathrm{N}$-bound is favoured while a negative value indicates top-hat is favoured.

\subsection{1. $\mathrm{D} 97 R p \mathrm{NiR}$}

Figure 2 indicates that within the timescale of the MD simulation the majority of the Tyr323 conformations are hydrogen bonded to Asp97 and positioned well into the substrate channel. However, a fraction of the conformations involves a disruption of the Tyr323-Asp97 hydrogen bond and a major displacement of Tyr323 from its position in the substrate channel. We therefore selected two snapshots to represent these possibilities. The first of these was taken at 72.53 ns where Tyr323 maintained an H-bond interaction with Asp97 in all three subunits. It represents the major conformational orientation observed from MD in this system (Figure 2a, left panel). The second snapshot was taken at 79.60 ns where the Tyr323 is displaced from the active site (Figure 2a,b, left panel) breaking its H-bond interaction with Asp97 in chain A, but in chains B and C it resides in the active site and forms an 
H-bond interaction with Asp97. As detailed in the Methods section optimizations were carried out separately for each monomeric unit, resulting in six independent starting structures. Relative energies and geometric descriptions of these are presented in Table S1.

1) Geometries of optimized $\mathrm{Cu}(\mathrm{II})$ and $\mathrm{Cu}(\mathrm{I})$ states starting from top-hat and N-bound orientations of $\mathrm{NO}_{2}^{-}$

In the case of $\mathrm{Cu}$ (II) starting from a top-hat orientation, all the relaxed structures retain the top-hat orientation, with both $\theta$ and $\psi$ within $170-180^{\circ}$. The nitrite oxygen atoms are roughly equidistant from $\mathrm{Cu}$, with distances differing by $\sim 0.3 \AA$ (Table S1). When reduced to $\mathrm{Cu}(\mathrm{I})$, the relaxed coordination changes to monodentate top-hat orientation with asymmetric $\mathrm{Cu}-\mathrm{O}$ distances. $\theta$ lies within the range from $160^{\circ}$ to $180^{\circ}$, with the majority of structures in the $170-180^{\circ}$ range, while $\psi$ is around $145-165^{\circ}$, a signature of monodentate $\mathrm{NO}_{2}{ }^{-}$in top-hat orientation. Here $\mathrm{Cu}$ is bound to $\mathrm{O}$, hence $\mathrm{N}$ is necessarily displaced, resulting in the azimuthal angle of $\sim 150^{\circ}$. In one conformation, $\theta$ is $159.1^{\circ}$, at the lower limit of the observed range.

Starting from N-bound orientations, there is more variation in the relaxed structures. All the final structures represent N-bound geometry with $\theta<10^{\circ}$. However, both symmetric $\left(\psi<10^{\circ}\right)$ and L-shaped $\left(\psi>10^{\circ}\right)$ orientations are observed. This is also reflected in the two Cu-O distances: for L-shaped N-bound structures, the difference between the two $\mathrm{Cu}-\mathrm{O}$ distances are $>0.3 \AA$. On reduction to $\mathrm{Cu}(\mathrm{I})$ we observe $\theta<10^{\circ}$ as in $\mathrm{Cu}(\mathrm{II})$, but the $\mathrm{N}$-bound structures are more symmetrical in nature, where $\psi<3^{\circ}$ and in many cases close to $0^{\circ}$, with the oxygen atoms therefore equidistant from $\mathrm{Cu}$. The range of $\theta$ and $\psi$ observed for this system across all the 6 structures are given in Table 3 . The angle $\varphi$ is in the range of $80-90^{\circ}$ and six angles around $\mathrm{Cu}$ are in the range of $90-135^{\circ}$, but in some cases, one of the $\mathrm{N}\left(\mathrm{NO}_{2}{ }^{-}\right)-\mathrm{T} 2 \mathrm{Cu}-\mathrm{N}(\mathrm{His})$ angles is larger and fell in the range of $140-162^{\circ}$ (Table S1). Overall the structures can be classified as tetrahedrally distorted trigonal geometries.

Table 3. Distribution of $\theta$ and $\psi$ angles for the optimised conformations.

\begin{tabular}{|c|c|c|c|c|c|c|c|}
\hline \multicolumn{2}{|c|}{ Geometrical Parameters and Distribution } & \multicolumn{3}{|c|}{$\mathrm{Cu}(\mathrm{II})$} & \multicolumn{3}{|c|}{$\mathrm{Cu}(\mathrm{I})$} \\
\hline & & D97 & D97p & D97N & D97 & D97p & D97N \\
\hline \multirow{3}{*}{ Bidentate top-hat } & $\theta /{ }^{\circ}$ & $175.8(1.1)$ & $178.1(1.6)$ & $177.7(1.7)$ & - & - & - \\
\hline & $\psi /{ }^{\circ}$ & $174.2(0.6)$ & $175.0(1.1)$ & $174.1(2.7)$ & - & - & - \\
\hline & $\%$ structures ${ }^{b}$ & 100 & 100 & 100 & - & - & - \\
\hline \multirow{3}{*}{ Monodentate top-hat } & $\theta /{ }^{\circ}$ & - & - & - & $175.5(3.9)$ & $174.5(4.8)$ & $175.3(5.4)$ \\
\hline & $\psi /{ }^{\circ}$ & - & - & - & $156.7(2.4)$ & $160.4(5.6)$ & $158.8(5.3)$ \\
\hline & $\%$ structures ${ }^{b}$ & - & - & - & $83.3^{a}$ & $71.4^{\mathrm{a}}$ & $66.7^{\mathrm{a}}$ \\
\hline \multirow{3}{*}{ L-shaped N-bound } & $\theta /^{\circ}$ & $5.8(1.1)$ & $6.1(1.5)$ & $5.1(2.4)$ & - & - & - \\
\hline & $\psi /{ }^{\circ}$ & $12.6(1.5)$ & $12.2(1.5)$ & $15.8(1.0)$ & - & - & - \\
\hline & $\%$ structures ${ }^{b}$ & 66.7 & 71.4 & 33.3 & - & - & - \\
\hline \multirow{3}{*}{ Symmetrical N-bound } & $\theta /{ }^{\circ}$ & $5.4^{\mathrm{c}}$ & $5.0^{\mathrm{c}}$ & $5.8(3.1)$ & $5.8(1.3)$ & $7.1(3.5)$ & $4.3(3.1)$ \\
\hline & $\psi / /^{\circ}$ & $6.6^{\mathrm{c}}$ & $4.9^{c}$ & $6.4(1.9)$ & $1.0(0.7)$ & $3.3(1.9)$ & $2.4(1.8)$ \\
\hline & $\%$ structures ${ }^{b}$ & 33.3 & 28.6 & 66.7 & 100 & 100 & 100 \\
\hline
\end{tabular}

${ }^{a}$ Outliers are not reported in the table, see text and Table S1. ${ }^{b}$ The percentage of structures which optimized to the orientations provided in the first column compared to the original starting structure. ${ }^{c}$ Average over two structures only.

2) Energetics of $\mathrm{Cu}(\mathrm{II})$ and $\mathrm{Cu}(\mathrm{I})$ states

In the case of $\mathrm{Cu}(\mathrm{II})$, for snapshots where the Tyr323 is engaged in a H-bond interaction with Asp97, the structures are mostly close in energy, and in one structure the bidentate orientation is favoured over the L-shaped $\mathrm{NO}_{2}{ }^{-}$orientation (Table S1). In the structure where Tyr323 is displaced from the T2Cu site, an extended H-bond network exists linking Tyr323 to Asp97 and the L-shaped N-bound structure has more favourable energy than the bidentate top-hat structure. The complex active site H-bond pattern as well as the interactions of the other active site residues is susceptible to the orientation of $\mathrm{NO}_{2}^{-}$at the $\mathrm{T} 2 \mathrm{Cu}$ site and likely contributes to the difference in energy observed in these structures. In Table 4 
the average energy difference $\Delta \mathrm{E}$ between the top-hat and N-bound structures is presented. For $\mathrm{Cu}(\mathrm{II})$ the structures are effectively isoenergetic.

Table 4. Average energy difference $\Delta \mathrm{E}=\mathrm{E}_{\text {top-hat }}-\mathrm{E}_{\mathrm{N} \text {-bound }}$ and standard deviation in $\mathrm{kcal} / \mathrm{mol}$ for $\mathrm{NO}_{2}{ }^{-}$binding in D97, D97p and D97N.

\begin{tabular}{cccc}
\hline System & Number of Starting Structures & Oxidation State & Average $\Delta$ E Energy in kcal/mol (std) \\
\hline \multirow{2}{*}{ D97 } & \multirow{2}{*}{6} & $\mathrm{Cu}(\mathrm{II})$ & $-0.27(2.96)$ \\
& \multirow{2}{*}{ D97p } & $\mathrm{Cu}(\mathrm{I})$ & $8.66(6.39)$ \\
& \multirow{2}{*}{ D97N } & $\mathrm{Cu}(\mathrm{II})$ & $0.24(2.73)$ \\
& \multirow{2}{*}{9} & $\mathrm{Cu}(\mathrm{I})$ & $4.64(7.66)$ \\
\hline
\end{tabular}

On reduction to $\mathrm{Cu}(\mathrm{I})$, the symmetrical $\mathrm{N}$-bound orientation of $\mathrm{NO}_{2}{ }^{-}$structures are energetically favoured over the corresponding monodentate top-hat structures. Unlike $\mathrm{Cu}(\mathrm{II})$, the D97 system indicates a clear trend in preference for a symmetrical N-bound orientation in the $\mathrm{Cu}(\mathrm{I})$ state (Table 4). Similar observations were obtained from previous calculations on other two-domain CuNiRs and model compounds representing the T2Cu site of CuNiRs [31,32].

\subsubsection{D97p RpNiR}

In contrast to the D97 system, protonation of Asp97 causes frequent transient disruption of the Tyr323-Asp97 H-bond (Figure 2a, middle panel), while in the timescale of the MD simulation no significant movement of Tyr323 from its position in the substrate channel is observed (Figure 2b, middle panel). Three representative snapshots were taken which differed by the number of monomeric units that featured the presence of a Tyr323-Asp97 H-bond: in all monomeric units (74.52 ns), in two of the three monomeric units (44.31 ns), and in one monomeric unit (48.40 ns) respectively. Optimization of these snapshots was carried out for all monomeric units, providing 9 independent conformations. Two structures in $\mathrm{Cu}$ (II) state resulted in orientations with very short $\mathrm{Cu}-\mathrm{O}$-Asp97 distance, which is not observed experimentally. These structures were discarded, resulting in 7 independent starting structures. Relative energies and geometric descriptions of all conformations are presented in Table S1.

1) Geometries of optimized $\mathrm{Cu}(\mathrm{II})$ and $\mathrm{Cu}(\mathrm{I})$ states starting from top-hat and N-bound orientations of $\mathrm{NO}_{2}^{-}$

In the case of $\mathrm{Cu}(\mathrm{II})$ starting from top-hat orientation, all the relaxed structures optimized in a bidentate top-hat orientation, with both $\theta$ and $\psi$ within the range $170-180^{\circ}$. The oxygens are approximately equidistant from $\mathrm{Cu}$, with distances differing by $\sim 0.3 \AA$. When reduced to $\mathrm{Cu}(\mathrm{I})$, the relaxed orientation changes to monodentate top-hat. In the majority of the structures $\theta$ is in the range of $170-180^{\circ}$. In two conformations, however, $\theta$ is $153.2^{\circ}$ and $145.0^{\circ}$, respectively falling outside the range given in Table 2. Such cases fall in the borderline between the top-hat and side-on categories. The azimuthal angle $\psi$ lies in the range $145-165^{\circ}$, the same as observed for the D97 system, which is a signature for monodentate top-hat orientation.

Similarly to the D97 system, the $\mathrm{Cu}$ (II) structures starting from an N-bound orientation show more structural variation than its $\mathrm{Cu}(\mathrm{II})$ top-hat counterpart. All the final structures feature an N-bound geometry with $\theta<10^{\circ}$; however both symmetric $\left(\psi<10^{\circ}\right)$ and L-shaped $\left(\psi>10^{\circ}\right)$ orientations are observed. This is also reflected in the two $\mathrm{Cu}-\mathrm{O}$ distances: for the L-shaped N-bound structures the difference between the two Cu-O distances are $>0.3 \AA$ (Table S1). On reduction to $\mathrm{Cu}(\mathrm{I})$, all N-bound structures have $\theta<20^{\circ}$ as shown in Table 2; with the majority within $\theta<10^{\circ}$. The L-shaped orientation is not observed, rather all of them fall in the category of symmetrical N-bound orientation with equidistant $\mathrm{O}$-atoms and $\psi<6^{\circ}$. In the majority of structures, the variation in $\psi$ is even less; $\psi<3^{\circ}$ (Table S1). The distribution of $\theta$ and $\psi$ observed for this system are also provided in Table 3 . The angle 
$\varphi$ is in the range of $78-90^{\circ}$ and six angles around $\mathrm{Cu}$ are in the range of $90-135^{\circ}$ but in a few cases one of the $\mathrm{N}\left(\mathrm{NO}_{2}{ }^{-}\right)-\mathrm{T} 2 \mathrm{Cu}-\mathrm{N}$ (His) angles is larger and fell in the range of $140-145^{\circ}$ (Table S1). Like D97, the geometries can overall be classified as tetrahedrally distorted trigonal structures.

2) Energetics of $\mathrm{Cu}(\mathrm{II})$ and $\mathrm{Cu}(\mathrm{I})$ states

In the $\mathrm{Cu}(\mathrm{II})$ case the energy difference between individual top-hat and N-bound structures is usually less than $5 \mathrm{kcal} / \mathrm{mol}$ (see Table S1) which could arise from small changes in the active site $\mathrm{H}$-bond network. There is no clear evidence of energetic differences arising from the orientation of the $\mathrm{NO}_{2}{ }^{-}$ion. Unlike the $\mathrm{D} 97$ system, there is a small trend towards symmetrical $\mathrm{N}$-bound structures over monodentate structures. Table 4 shows the average $\Delta \mathrm{E}$ for both $\mathrm{Cu}(\mathrm{I})$ and $\mathrm{Cu}(\mathrm{II})$ states. For $\mathrm{Cu}$ (II) the structures are effectively isoenergetic with a small standard deviation, whereas for $\mathrm{Cu}(\mathrm{I})$ the average $\Delta \mathrm{E}$ suggests that $\mathrm{N}$-bound is favoured, but with a large standard deviation showing there is significant variations over the snapshots.

\subsubsection{D97N Mutant $R p N i R$}

As with the D97p system, a mutation of Asp97 to Asn weakens the hydrogen bond between Asn97 and Tyr323 causing frequent transient disruption of the H-bond interaction (Figure 2a, right panel). Another similarity with the D97p system is an absence of significant movement of Tyr323 from its initial position in the substrate channel (Figure $2 b$, right panel). Three representative snapshots were taken which differed according to the number of monomeric units for which the Tyr323-Asn97 H-bond was absent: in all monomeric units (25.54 ns), in two of the three monomeric units (27.86 ns) and in one monomeric unit ( $64.95 \mathrm{~ns})$ respectively. An additional snapshot at $78.48 \mathrm{~ns}$ was added in the last category, to represent the situation where Tyr323 is H-bonded to O-Asn in one monomeric unit like the $64.95 \mathrm{~ns}$ snapshot and in the other is H-bonded via N-Asn. Optimization was carried out for each of the monomeric units providing 12 independent conformations, of which 3 conformations are not reported due to the presence of a short $\mathrm{Cu}$-OAsn97 bond that is not observed in $\mathrm{CuNiR}$ crystal structures. This leaves a total of 9 conformations that are studied for this mutant system. Relative energies and geometric descriptions of all conformations are presented in Table S1.

1) Geometries of optimized $\mathrm{Cu}(\mathrm{II})$ and $\mathrm{Cu}(\mathrm{I})$ states starting from top-hat and N-bound orientations of $\mathrm{NO}_{2}{ }^{-}$

Optimization of top-hat $\mathrm{Cu}$ (II) structures resulted in bidentate top-hat orientation, with both $\theta$ and $\psi$ within the range $170-180^{\circ}$ as categorised in Table 2 . The oxygen atoms are approximately equidistant from $\mathrm{Cu}$, with distances differing by $\sim 0.3 \AA$. When reduced to $\mathrm{Cu}(\mathrm{I})$, the relaxed coordination changes to a monodentate top-hat orientation. $\theta$ ranges from $160^{\circ}$ to $180^{\circ}$, with the majority of structures within 170-180 . Unlike for D97 and D97p, in one conformation a side-on orientation of $\mathrm{NO}_{2}{ }^{-}$is observed $\left(\theta\right.$ and $\psi \sim 88^{\circ}$ ). This is consistent with data for the two-domain $\mathrm{CuNiR}$, whose T2Cu site lacks the linker residue [21]. Another conformation falls in the borderline of top-hat and side on with $\theta=149.4^{\circ}$. In most of the structures the value of $\psi$ is around $145-165^{\circ}$ as observed for D97 and D97p systems and implies a monodentate top-hat orientation. There is another outlier, where $\psi$ is $172.1^{\circ}$ and is of bidentate nature. Again, as with the D97 and D97p systems more structural variations were observed starting from the $\mathrm{N}$-bound $\mathrm{NO}_{2}{ }^{-}$orientation. All the final $\mathrm{Cu}(\mathrm{II})$ structures feature an $\mathrm{N}$-bound geometry with $\theta<10^{\circ}$; however symmetrical N-bound structures $\left(\psi<10^{\circ}\right)$ are more abundant than the L-shaped $\mathrm{N}$-bound $\left(\psi>10^{\circ}\right)$ ones. In one N-bound case a penta-coordination around $\mathrm{T} 2 \mathrm{Cu}$ is observed with symmetrical $\mathrm{N}$-bound $\mathrm{NO}_{2}{ }^{-}$and a water. On reduction to $\mathrm{Cu}(\mathrm{I})$, the structures relaxed to symmetrical N-bound orientation with $\theta<10^{\circ}$, and in the majority of structures $\psi<3^{\circ}$. For two structures $\psi$ values of $4.3^{\circ}$ and $6.0^{\circ}$ were observed, but this is still well within the thresholds defined in Table 2. The distribution of these two geometrical parameters is provided in Table 3 along with the same for other two systems. The angle $\varphi$ is in the range of $79-90^{\circ}$ and six angles around $\mathrm{Cu}$ are in the range of $90-135^{\circ}$. Like the D97 and D97p systems, in some cases one of the $\mathrm{N}\left(\mathrm{NO}_{2}{ }^{-}\right)-\mathrm{T} 2 \mathrm{Cu}-\mathrm{N}(\mathrm{His})$ 
angle is larger and fell in the range of $140-157^{\circ}$ (Table S1), hence, the overall structures are classified as tetrahedrally distorted trigonal structures.

2) Energetics of $\mathrm{Cu}(\mathrm{II})$ and $\mathrm{Cu}(\mathrm{I})$ states

In the $\mathrm{Cu}(\mathrm{II})$ case the individual energy differences between top-hat and $\mathrm{N}$-bound structures are slightly higher than observed for the D97p systems; the maximum difference ranging up to $8 \mathrm{kcal} / \mathrm{mol}$ (see Table S1). The distribution of $\mathrm{N}$-bound orientations in $\mathrm{Cu}(\mathrm{I})$ state slightly exceeds the top-hat orientations. In this system too, there is no clear correlation between the orientation of the $\mathrm{NO}_{2}{ }^{-}$at the active site and the energy variation. The average $\Delta \mathrm{E}$ for both $\mathrm{Cu}(\mathrm{I})$ and $\mathrm{Cu}(\mathrm{II})$ states is provided in Table 4.

Here we see that for $\mathrm{Cu}(\mathrm{II})$ the average energy difference suggests that top-hat may be marginally favoured overall but with significant variation between snapshots as indicated by the large standard deviation. For $\mathrm{Cu}(\mathrm{I})$ the result is clearer cut with N-bound favoured over top-hat overall.

\section{Discussion}

The MD simulations in this work reveal an important consequence of the flexibility of the linker region in $R p N i R$. They suggest that Tyr323 does not rigidly block the substrate access channel to the active site, rather it is flexible and can be displaced by the natural water dynamics in the resting state of the enzyme, causing the channel to open, which would allow $\mathrm{NO}$ or $\mathrm{NO}_{2}{ }^{-}$to enter or leave the catalytic site. The MD corroborates the findings of Dong et al. for the D97N mutant [20], who observed displacement of Tyr323 for the NO-bound structure, resulting in an opening up of the channel. It is well known that sampling of the full configurational space is not possible in the time limit of typical all-atom MD simulations, and future work will use enhanced sampling methods to explore the flexibility of the Tyr323 residue and substrate entry to the $\mathrm{T} 2 \mathrm{Cu}$.

A striking difference between the crystal structure of mutant $R p N i R$ and two-domain CuNiRs is the mode of $\mathrm{NO}_{2}{ }^{-}$binding; in two-domain $\mathrm{NiRs} \mathrm{NO}_{2}{ }^{-}$binds in a bidentate top-hat orientation to $\mathrm{T} 2 \mathrm{Cu}$ whereas in the $\mathrm{RpNiR}$ mutant an $\mathrm{N}$-bound orientation was observed [20]. In this work we have investigated the orientation of nitrite binding to $\mathrm{T} 2 \mathrm{Cu}$ for both oxidized $\mathrm{Cu}(\mathrm{II})$ and reduced $\mathrm{Cu}(\mathrm{I})$ states of native and mutant $R p N i R$. To categorize the different modes by which $\mathrm{NO}_{2}{ }^{-}$can bind to the T2Cu we introduced two geometrical parameters, $\theta$ and $\psi$, and observed that the conformations obtained on $\mathrm{QM} / \mathrm{MM}$ optimization of the nitrite bound structures clustered into particular ranges. Figure 4 shows representative structures of the four clusters of geometries as classified by $\theta$ and $\psi$, which we label bidentate top-hat, monodentate top-hat, L-shaped N-bound and symmetric N-bound.

There were however a few structures which adopted other orientations: one $\mathrm{Cu}(\mathrm{I})$ conformer in D97N optimized to a side-on $\mathrm{NO}_{2}{ }^{-}$orientation, and one $\mathrm{Cu}(\mathrm{I})$ conformer in $\mathrm{D} 97 \mathrm{~N}$ and two $\mathrm{Cu}(\mathrm{I})$ conformers in D97p have $\theta$ values of approximately $150^{\circ}$, which lies in-between top-hat and side-on orientation. The side-on orientation was seen in MSOX data for the reduced $\mathrm{Cu}(\mathrm{I})$ state for $A c \mathrm{NiR}$ [21], and hence could be a viable ligand orientation for binding to reduced $R p \mathrm{NiR}$.

The twist angle, $\varphi$, though originally used to define the type I Cu coordination geometry, can also be extrapolated to define the geometry around the T2Cu site [29]. In the case of $R p N i R$, for all the systems studied $\varphi$ is in the range of $80-90^{\circ}$, inclining towards trigonal structures. Considering the His-Cu- $\mathrm{NO}_{2}{ }^{-}$and His-Cu-His angles along with $\varphi$, the structures are best classified as tetrahedrally distorted trigonal structures. In the work of Karllot et al. two distinct clustering of $\varphi$ with maximum $\mathrm{N}(\mathrm{His})-\mathrm{Cu}-\mathrm{N}(\mathrm{His})$ angle was observed in the reported crystal structures of all two-domain NiRs [29]. One had $\varphi$ in the range of $82-89^{\circ}$ and maximum N(His)-Cu-N(His) angles around $111-125^{\circ}$ whereas in the other $\varphi$ was in the range of $65-77^{\circ}$ and the maximum $\mathrm{N}(\mathrm{His})-\mathrm{Cu}-\mathrm{N}(\mathrm{His})$ angles around $134-162^{\circ}$. In our calculations on $R p \mathrm{NiR}$, however, we only find clustering of the former category.

In the oxidized $\mathrm{Cu}(\mathrm{II})$ state the relative stabilities of the N-bound and top-hat states is not clear cut. However, for the reduced $\mathrm{Cu}(\mathrm{I})$ state there is a slight preference for the N-bound state in both the D97p and D97N systems and a clear preference for it in the D97 system (Table 4). The origin of the 
energy difference, however, cannot be solely related to the orientation of the $\mathrm{NO}_{2}{ }^{-}$but to a complex interplay of the orientation as well as H-bond network in the active site.

(a) Bidentate Top-hat

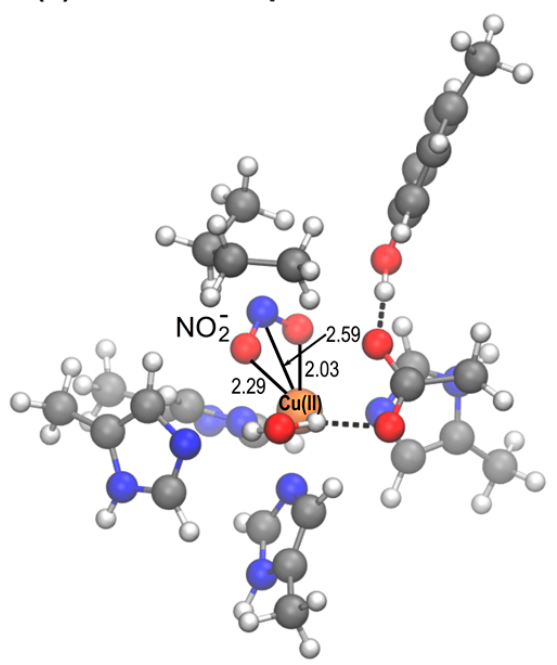

(c) Monodentate Top-hat (b) Asymmetric (L-shaped) N-Bound

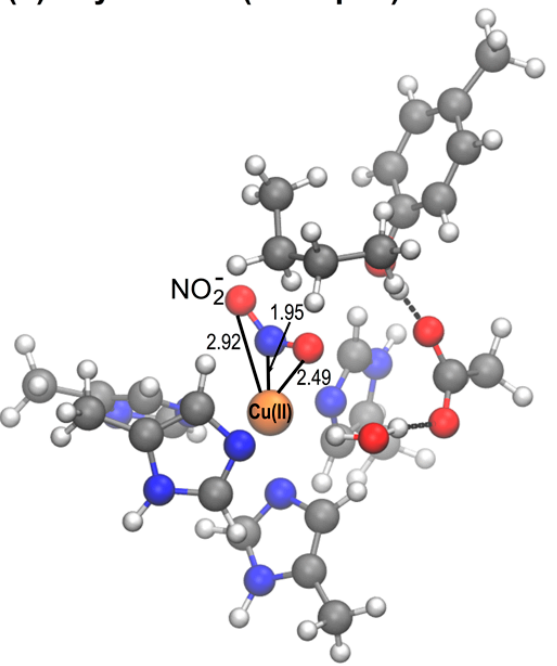

(d) Symmetric N-Bound

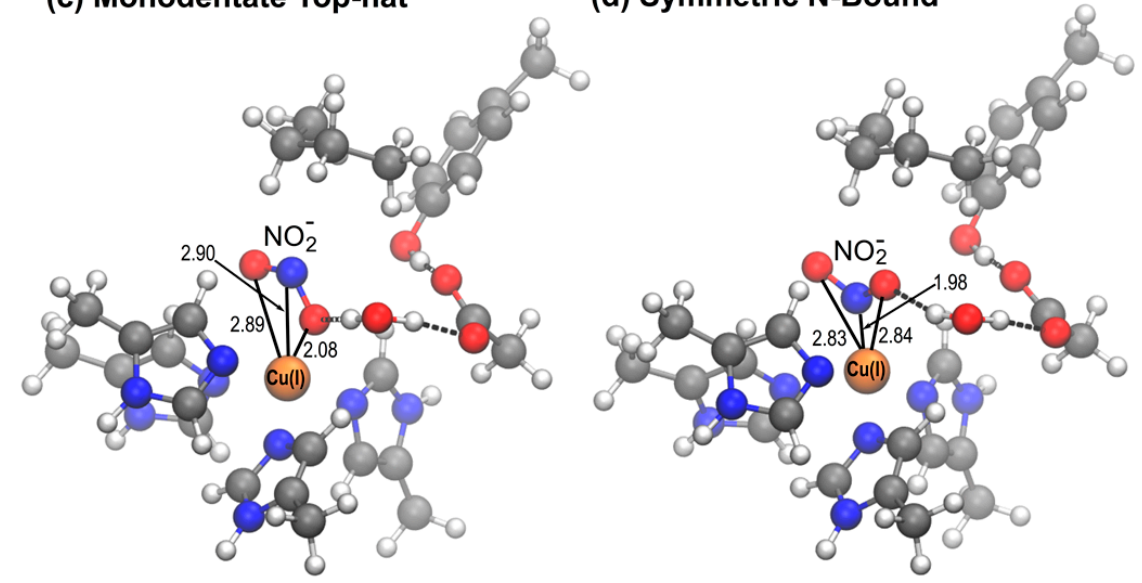

Figure 4. Representative structures of different orientations of $\mathrm{NO}_{2}{ }^{-}$bound to $\mathrm{T} 2 \mathrm{Cu}$ as classified by the geometric angles $\theta$ and $\psi$. (a) bidentate top-hat orientation, seen only in the $\mathrm{Cu}(\mathrm{II})$ state, (b) L-shaped $\mathrm{N}$-bound orientation, more common in the $\mathrm{Cu}(\mathrm{II})$ state, (c) monodentate top-hat orientation observed in relaxed top-hat geometries after reduction to $\mathrm{Cu}(\mathrm{I})$, (d) symmetrical N-bound orientation observed in both the oxidised and reduced states on relaxation from the N-bound state.

Figure 5 shows the overlay of the X-ray structures of the nitrite-bound D97N mutant [20] and two simulated conformers, from the D97 and D97N systems, with similar L-shaped $\mathrm{NO}_{2}{ }^{-}$orientations bound to $\mathrm{Cu}(\mathrm{II})$. In both systems, the Tyr323 was oriented in the substrate access channel as in the native $R p N i R$ crystal structure, rather than being displaced as observed experimentally for D97N. Apart from the difference in the Tyr323 position, the orientation of $\mathrm{NO}_{2}{ }^{-}$, the coordinated histidines and the other active site residues are all similar to the observed X-ray structure. In the crystal structure $\theta$ is $4.9^{\circ}$ and $\psi$ is $45.2^{\circ}$ and the corresponding angles from the optimized structures are $\theta: 5.8^{\circ}, 3.5^{\circ}$ and $\psi: 11.3^{\circ}, 16.3^{\circ}$. Our findings indicate that the X-ray structure is consistent with the L-shaped $\mathrm{N}$-bound $\mathrm{NO}_{2}{ }^{-}$orientations observed for the $\mathrm{Cu}(\mathrm{II})$ state in $R p N i R$ and not the reduced $\mathrm{Cu}(\mathrm{I})$ state (SI, Figure S2), owing to the symmetrical N-bound orientation we observe in the reduced state. Such an L-shaped orientation is not primarily observed for two-domain CuNiRs in the Cu(II) state where a bidentate top-hat orientation of $\mathrm{NO}_{2}{ }^{-}$is mostly prevalent. 


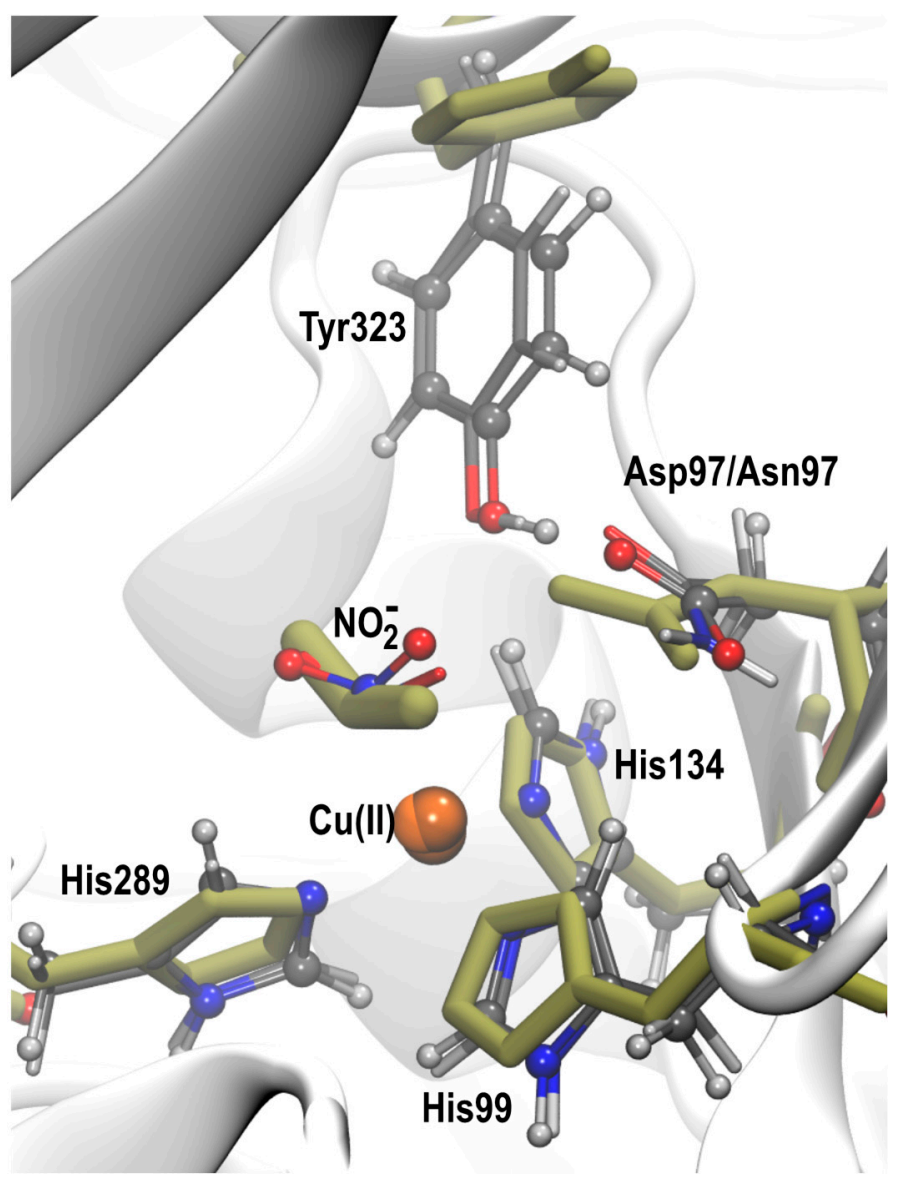

Figure 5. Superposition of the $\mathrm{NO}_{2}{ }^{-}$bound X-ray structure of $\mathrm{D} 97 \mathrm{~N} R p \mathrm{NiR}$ (olive sticks) and two L-shaped N-bound conformers, obtained by simulations from an initially $\mathrm{N}$-bound $\mathrm{NO}_{2}{ }^{-}$to the $\mathrm{Cu}$ (II) state in the D97 and D97N systems.

\section{Materials and Methods}

Nitrite binding to native $R p N i R$ has not been structurally characterised experimentally to date and only very recently has nitrite binding in a mutant (D97N) been reported [20]. We used a native structure of $R p N i R$ in its resting state as a template to study the mode of nitrite binding to the T2Cu site. The native crystal structure at $1.01 \AA$ resolution [9] was taken from the PDB databank (PDB ID: 3ZIY). The structure was first 'cleaned' for MD simulations by removing all double occupancy mainchain and sidechain atoms and partial water molecules, keeping those with greater fractional occupancy or lower B-factors. The homotrimeric biological unit was generated by symmetry operations using the clean version. Hydrogen atoms were added and the protonation states of the titratable residues apart from those at the active site were adjusted to be consistent with neutral $\mathrm{pH}$ using the propKa module of the PDB2PQR suite [33], followed by visual inspection of the local side-chain environments. The protonation states of the catalytically important residues, Asp97 (D97) and His240, were treated carefully. The residue His240 was singly protonated as HSD but the residue Asp97, the main residue involved in proton transfer, was considered in both its deprotonated and protonated forms in the native state. An in silico mutation to obtain $\mathrm{D} 97 \mathrm{~N}$ was performed on the native $R p \mathrm{NiR}$ structure, so that Tyr323 retained the same initial orientation in the substrate channel/T2Cu pocket in all three systems being investigated: D97, D97p and D97N.

The prepared structures corresponding to the three systems were then solvated with a $15 \AA$ layer of TIP3P water [34]. The electroneutrality of the D97, D97p and D97N systems were maintained by adding 6, 3, and 3 sodium counterions, respectively. Explicit all-atom MD simulations were performed on these systems using NAMD 2.9 [35] with the CHARMM36 force field [36]. These simulations 
employed Langevin dynamics with periodic boundary conditions at $293 \mathrm{~K}$. Long range electrostatics were treated by the Particle Mesh Ewald method. In the NPT simulations the pressure was maintained with the Langevin piston method. Both the systems were initially subjected to 5000 steps of conjugate gradient (CG) minimization to eliminate any unphysical contacts. Next, the water and ions were equilibrated using an NVT ensemble, keeping the protein fixed for $1 \mathrm{~ns}$. This was followed by 5000 steps of CG minimization and 5 ns equilibration under an NPT ensemble, keeping the backbone harmonically restrained $\left(5 \mathrm{kcal}^{-1} \mathrm{~mol}^{-1} \AA^{2}\right)$ and the coordination spheres of both the T1 and T2 sites $\left(\mathrm{Cu}(\mathrm{His})_{2}(\mathrm{Met})\left(\mathrm{Cys}^{-}\right)\right.$and $\mathrm{Cu}(\mathrm{His})_{3}\left(\mathrm{H}_{2} \mathrm{O}\right)$, respectively) constrained at their crystallographic coordinates. The simulation was continued for another $75 \mathrm{~ns}$ after removing the backbone restraints and allowing the coordinated water to move freely. The trajectories obtained from the MD simulations were analysed using VMD [37].

Snapshots were taken from the equilibrated MD trajectory as a starting point for QM/MM optimizations. The location of Tyr323 in the active site and the H-bond interaction of Tyr323 with Asp/Asn97 were used as the essential criteria for selecting the snapshots of both the native and mutant systems as detailed in the results section for each system. To obtain $\mathrm{NO}_{2}{ }^{-}$bound structures, these selected snapshots were overlaid with the analogous "top-hat" $\mathrm{NO}_{2}{ }^{-}$coordinates from the nitrite bound $A c \mathrm{NiR}$ structure [38]. The water(s) coordinated to $\mathrm{Cu}$ and any nearby water molecules that were in unphysically close steric interaction with the overlaid $\mathrm{NO}_{2}{ }^{-}$ion were then deleted. The nitrite coordinates were flipped to create analogous starting structures for the N-bound optimisations. In the absence of experimental data of the binding mode, this approach ensured that there was no bias in the initial starting structures towards either the top-hat or N-bound orientations.

The forces acting on the monomers along the simulation diverge, thus, the conformational arrangement at the catalytic sites which are housed at the interphase of two monomeric units are independent of one another, providing three independent starting structures in each snapshot. All these structures were subjected to QM/MM optimization of the nitrite bound T2Cu site following the standard QM/MM partition scheme. The QM region consists of the three histidine residues coordinating $\mathrm{T} 2 \mathrm{Cu}$ (His99, His134 and His289), the $\mathrm{NO}_{2}{ }^{-}$ligand, the three important active site residues Asp/Asn97, His240, and Ile242, the Tyr323 side chain, and any water molecules immediately H-bonded to Asp/Asn97, His240, Tyr323 and the $\mathrm{NO}_{2}{ }^{-}$ligand. The residues were cut at the neutral $\mathrm{C} \alpha-\mathrm{C} \beta$ bond and were capped with $\mathrm{H}$-atoms to satisfy the valency for the QM calculations. Atoms within $7 \AA$ of the QM region remained unconstrained during QM/MM geometry optimizations while the remaining atoms were frozen. The QM/MM optimizations were carried out for both the oxidized $\mathrm{Cu}(\mathrm{II})$ and reduced $\mathrm{Cu}(\mathrm{I})$ states of $\mathrm{Cu}$ starting from two orientations of $\mathrm{NO}_{2}{ }^{-}$: the $\eta^{2-} \mathrm{OO}$ (bidentate) 'top-hat' and $\eta^{1}-\mathrm{N}$ (monodentate) 'N-bound', to ensure that the potential energy surface was sufficiently explored. QM/MM calculations were performed with the Tcl-based version of the ChemShell computational chemistry environment [39,40], using ORCA [41] and DL_POLY [42] for the density functional theory and MM calculations respectively, and the DL-FIND module for geometry optimisations [43]. The electrostatic embedding scheme with charge shift correction was used to represent the surrounding MM partial charge distribution. The density functional B3LYP [44] with the DFT-D3 dispersion correction [45] was used for the QM atoms during geometry optimization and def2 ${ }^{-}$SVP basis sets were used for all QM atoms except $\mathrm{Cu}$, which was treated with the def2 ${ }^{-}$TZVP basis set [46]. The CHARMM36 force field was used for the MM region.

Supplementary Materials: The supplementary materials are available online, Figure S1: Overlap of the $\mathrm{NO}_{2}{ }^{-}$ bound X-ray structure of D97N and the frame at 79.6 ns of D97 MD in its resting state. Chain A, where the Tyr is displaced (Figure 3 in main text) is highlighted here. The coordination around the T2Cu site and active site residues Asp97 and Tyr323 illustrate the similarity in the position of Asp97 and displacement of Tyr323 in MD that structurally matches the mutant crystal structure; Figure S2: Overlap of the $\mathrm{NO}_{2}{ }^{-}$bound X-ray structure of D97N and two symmetrical N-bound conformers obtained from an initially $\mathrm{N}$-bound $\mathrm{NO}_{2}{ }^{-}$in the $\mathrm{Cu}(\mathrm{I})$ state of the D97 and D97N systems; Table S1: Geometric parameters and energies for the optimized conformers obtained from the D97, D97p and D97N systems. The distances are $\mathrm{Cu}-\mathrm{N}, \mathrm{Cu}-\mathrm{O} 1$ and $\mathrm{Cu}-\mathrm{O} 2$, respectively, where $\mathrm{O} 1$ and $\mathrm{O} 2$ are the two equivalent $\mathrm{O}$-atoms of $\mathrm{NO}_{2}{ }^{-}$. 
Author Contributions: Conceptualization, all authors; Methodology, all authors; Software, T.W.K.; Validation, all authors; Formal Analysis, K.S., C.W.Y. and T.W.K.; Investigation, K.S.; Resources, R.W.S., M.A.H., C.W.Y. and T.W.K.; Data Curation, K.S.; Writing-Original Draft Preparation, K.S.; Writing-Review \& Editing, all authors; Visualization, K.S.; Supervision, R.W.S. and T.W.K.; Project Administration, R.W.S.; Funding Acquisition, R.W.S., M.A.H., C.W.Y. and T.W.K.

Funding: This research was funded by BBSRC grant numbers BB/M020924/1 to R.W.S., BB/M022714/1 to M.A.H. and BB/M022390/1 to T.W.K.

Acknowledgments: We acknowledge the Hartree Centre at STFC Daresbury Laboratory for provision of computational resources on the Blue Wonder cluster and the Scientific Computing Department at STFC for computational resources provided by the SCARF Cluster. We thank Samar Hasnain, Robert Eady and Svetlana Antonyuk at the University of Liverpool for helpful discussions during the initial stages of this project.

Conflicts of Interest: The authors declare no conflict of interest.

\section{References}

1. Maia, L.B.; Moura, J.J. How biology handles nitrite. Chem. Rev. 2014, 114, 5273-5357. [CrossRef] [PubMed]

2. Zumft, W.G. Cell biology and the molecular basis of denitrification. Microbiol. Mol. Biol. Rev. 1997, 61, 533-616. [PubMed]

3. Eady, R.R.; Hasnain, S.S. Comprehensive Coordination Chemistry II: Bio-Coordination Chemistry; Que, L.T.W., Tolman, W., Eds.; Elsevier: Oxford, UK, 2003; Volume 8, pp. 759-786.

4. Nojiri, M.; Xie, Y.; Inoue, T.; Yamamoto, T.; Matsumura, H.; Kataoka, K.; Deligeer; Yamaguchi, K.; Kai, Y.; Suzuki, S. Structure and function of a hexameric copper-containing nitrite reductase. Proc. Natl. Acad. Sci. USA 2007, 104, 4315-4320. [CrossRef] [PubMed]

5. Yamaguchi, K.; Kataoka, K.; Kobayashi, M.; Itoh, K.; Fukui, A.; Suzuki, S. Characterization of two type $1 \mathrm{Cu}$ sites of Hyphomicrobium denitrificans nitrite reductase: A new class of copper-containing nitrite reductases. Biochemistry 2004, 43, 14180-14188. [CrossRef] [PubMed]

6. Bertini, I.; Cavallaro, G.; Rosato, A. Cytochrome c: Occurrence and functions. Chem. Rev. 2006, 106, 90-115. [CrossRef] [PubMed]

7. Han, C.; Wright, G.S.; Fisher, K.; Rigby, S.E.; Eady, R.R.; Hasnain, S.S. Characterization of a novel copper-haem c dissimilatory nitrite reductase from Ralstonia pickettii. Biochem. J. 2012, 444, 219-226. [CrossRef] [PubMed]

8. Ellis, M.J.; Grossmann, J.G.; Eady, R.R.; Hasnain, S.S. Genomic analysis reveals widespread occurrence of new classes of copper nitrite reductases. J. Biol. Inorg. Chem. 2007, 12, 1119-1127. [CrossRef] [PubMed]

9. Antonyuk, S.V.; Han, C.; Eady, R.R.; Hasnain, S.S. Structures of protein-protein complexes involved in electron transfer. Nature 2013, 496, 123-126. [CrossRef] [PubMed]

10. Antonyuk, S.V.; Strange, R.W.; Sawers, G.; Eady, R.R.; Hasnain, S.S. Atomic resolution structures of resting-state, substrate- and product-complexed $\mathrm{Cu}$-nitrite reductase provide insight into catalytic mechanism. Proc. Natl. Acad. Sci. USA 2005, 102, 12041-12046. [CrossRef] [PubMed]

11. Ellis, M.J.; Dodd, F.E.; Sawers, G.; Eady, R.R.; Hasnain, S.S. Atomic resolution structures of native copper nitrite reductase from Alcaligenes xylosoxidans and the active site mutant Asp92Glu. J. Mol. Biol. 2003, 328, 429-438. [CrossRef]

12. Leferink, N.G.; Antonyuk, S.V.; Houwman, J.A.; Scrutton, N.S.; Eady, R.R.; Hasnain, S.S. Impact of residues remote from the catalytic centre on enzyme catalysis of copper nitrite reductase. Nat. Commun. 2014, 5, 4395. [CrossRef] [PubMed]

13. Fukuda, Y.; Tse, K.M.; Lintuluoto, M.; Fukunishi, Y.; Mizohata, E.; Matsumura, H.; Takami, H.; Nojiri, M.; Inoue, T. Structural insights into the function of a thermostable copper-containing nitrite reductase. J. Biochem. 2014, 155, 123-135. [CrossRef] [PubMed]

14. Sen, K.; Horrell, S.; Kekilli, D.; Yong, C.W.; Keal, T.W.; Atakisi, H.; Moreau, D.W.; Thorne, R.E.; Hough, M.A.; Strange, R.W. Active-site protein dynamics and solvent accessibility in native Achromobacter cycloclastes copper nitrite reductase. IUCrJ 2017, 4, 495-505. [CrossRef] [PubMed]

15. Tocheva, E.I.; Eltis, L.D.; Murphy, M.E. Conserved active site residues limit inhibition of a copper-containing nitrite reductase by small molecules. Biochemistry 2008, 47, 4452-4460. [CrossRef] [PubMed]

16. Boulanger, M.J.; Kukimoto, M.; Nishiyama, M.; Horinouchi, S.; Murphy, M.E. Catalytic roles for two water bridged residues (Asp-98 and His-255) in the active site of copper-containing nitrite reductase. J. Biol. Chem. 2000, 275, 23957-23964. [CrossRef] [PubMed] 
17. Ellis, M.J.; Prudencio, M.; Dodd, F.E.; Strange, R.W.; Sawers, G.; Eady, R.R.; Hasnain, S.S. Biochemical and crystallographic studies of the Met144Ala, Asp92Asn and His254Phe mutants of the nitrite reductase from Alcaligenes xylosoxidans provide insight into the enzyme mechanism. J. Mol. Biol. 2002, 316, 51-64. [CrossRef] [PubMed]

18. Kataoka, K.; Furusawa, H.; Takagi, K.; Yamaguchi, K.; Suzuki, S. Functional Analysis of Conserved Aspartate and Histidine Residues Located Around the Type 2 Copper Site of Copper-Containing Nitri Reductase. J. Biochem. 2000, 127, 345-350. [CrossRef] [PubMed]

19. Prudencio, M.; Eady, R.R.; Sawers, G. Catalytic and spectroscopic analysis of blue copper-containing nitrite reductase mutants altered in the environment of the type 2 copper centre: Implications for substrate interaction. Biochem. J. 2001, 353, 259-266. [CrossRef] [PubMed]

20. Dong, J.; Sasaki, D.; Eady, R.R.; Antonyuk, S.V.; Hasnain, S.S. Identification of a tyrosine switch in copper-haem nitrite reductases. IUCrJ 2018, 5, 510-518. [CrossRef] [PubMed]

21. Horrell, S.; Kekilli, D.; Sen, K.; Owen, R.L.; Dworkowski, F.S.N.; Antonyuk, S.V.; Keal, T.W.; Yong, C.W.; Eady, R.R.; Hasnain, S.S.; et al. Enzyme catalysis captured using multiple structures from one crystal at varying temperatures. IUCrJ 2018, 5, 283-292. [CrossRef] [PubMed]

22. Boulanger, M.J.; Murphy, M.E. Directing the mode of nitrite binding to a copper-containing nitrite reductase from Alcaligenes faecalis S-6: Characterization of an active site isoleucine. Protein Sci. 2003, 12, 248-256. [CrossRef] [PubMed]

23. Dodd, F.E.; Hasnain, S.S.; Abraham, Z.H.; Eady, R.R.; Smith, B.E. Structures of a blue-copper nitrite reductase and its substrate-bound complex. Acta Crystallogr. D Biol. Crystallogr. 1997, 53, 406-418. [CrossRef] [PubMed]

24. Brenner, S.; Heyes, D.J.; Hay, S.; Hough, M.A.; Eady, R.R.; Hasnain, S.S.; Scrutton, N.S. Demonstration of proton-coupled electron transfer in the copper-containing nitrite reductases. J. Biol. Chem. 2009, 284, 25973-25983. [CrossRef] [PubMed]

25. Hough, M.A.; Antonyuk, S.V.; Strange, R.W.; Eady, R.R.; Hasnain, S.S. Crystallography with online optical and X-ray absorption spectroscopies demonstrates an ordered mechanism in copper nitrite reductase. J. Mol. Biol. 2008, 378, 353-361. [CrossRef] [PubMed]

26. Ghosh, S.; Dey, A.; Sun, Y.; Scholes, C.P.; Solomon, E.I. Spectroscopic and computational studies of nitrite reductase: Proton induced electron transfer and backbonding contributions to reactivity. J. Am. Chem. Soc. 2009, 131, 277-288. [CrossRef] [PubMed]

27. Wijma, H.J.; Jeuken, L.J.; Verbeet, M.P.; Armstrong, F.A.; Canters, G.W. A random-sequential mechanism for nitrite binding and active site reduction in copper-containing nitrite reductase. J. Biol. Chem. 2006, 281, 16340-16346. [CrossRef] [PubMed]

28. Goldsmith, R.H.; Tabares, L.C.; Kostrz, D.; Dennison, C.; Aartsma, T.J.; Canters, G.W.; Moerner, W.E. Redox cycling and kinetic analysis of single molecules of solution-phase nitrite reductase. Proc. Natl. Acad. Sci. USA 2011, 108, 17269-17274. [CrossRef] [PubMed]

29. Källrot, N.; Nilsson, K.; Rasmussen, T.; Ryde, U. Theoretical study of structure of catalytic copper site in nitrite reductase. Int. J. Quantum Chem. 2005, 102, 520-541. [CrossRef]

30. Olsson, M.H.M.; Ryde, U.; Roos, B.O.; Pierloot, K. On the relative stability of tetragonal and trigonal Cu(II) complexes with relevance to the blue copper proteins. J. Biol. Inorg. Chem. 1998, 3, 109-125. [CrossRef]

31. Sundararajan, M.; Hillier, I.H.; Burton, N.A. Mechanism of nitrite reduction at T2Cu centers: Electronic structure calculations of catalysis by copper nitrite reductase and by synthetic model compounds. J. Phys. Chem. B 2007, 111, 5511-5517. [CrossRef] [PubMed]

32. Silaghi-Dumitrescu, R. Copper-containing nitrite reductase: A DFT study of nitrite and nitric oxide adducts. J. Inorg. Biochem. 2006, 100, 396-402. [CrossRef] [PubMed]

33. Dolinsky, T.J.; Nielsen, J.E.; McCammon, J.A.; Baker, N.A. PDB2PQR: An automated pipeline for the setup of Poisson-Boltzmann electrostatics calculations. Nucleic Acids Res. 2004, 32, W665-W667. [CrossRef] [PubMed]

34. Jorgensen, W.L.; Chandrasekhar, J.; Madura, J.D.; Impey, R.W.; Klein, M.L. Comparison of Simple Potential Functions for Simulating Liquid Water. J. Chem. Phys. 1983, 79, 926-935. [CrossRef]

35. Phillips, J.C.; Braun, R.; Wang, W.; Gumbart, J.; Tajkhorshid, E.; Villa, E.; Chipot, C.; Skeel, R.D.; Kalé, L.; Schulten, K. Scalable molecular dynamics with NAMD. J. Comput. Chem. 2005, 26, 1781-1802. [CrossRef] [PubMed] 
36. Best, R.B.; Zhu, X.; Shim, J.; Lopes, P.E.; Mittal, J.; Feig, M.; Mackerell, A.D., Jr. Optimization of the additive CHARMM all-atom protein force field targeting improved sampling of the backbone $\varphi, \psi$ and side-chain $\chi_{1}$ and $\chi_{2}$ dihedral angles. J. Chem. Theory Comput. 2012, 8, 3257-3273. [CrossRef] [PubMed]

37. Humphrey, W.; Dalke, A.; Schulten, K. VMD: Visual molecular dynamics. J. Mol. Graph. 1996, 14, 33-38. [CrossRef]

38. Horrell, S.; Antonyuk, S.V.; Eady, R.R.; Hasnain, S.S.; Hough, M.A.; Strange, R.W. Serial crystallography captures enzyme catalysis in copper nitrite reductase at atomic resolution from one crystal. IUCrJ 2016, 3, 271-281. [CrossRef] [PubMed]

39. Sherwood, P.; de Vries, A.H.; Guest, M.F.; Schreckenbach, G.; Catlow, C.R.A.; French, S.A.; Sokol, A.A.; Bromley, S.T.; Thiel, W.; Turner, A.J.; et al. QUASI: A general purpose implementation of the QM/MM approach and its application to problems in catalysis. J. Mol. Struct. Theochem. 2003, 632, 1-28. [CrossRef]

40. Metz, S.; Kästner, J.; Sokol, A.A.; Keal, T.W.; Sherwood, P. ChemShell-A modular software package for QM/MM simulations. WIREs Comput. Mol. Sci. 2014, 4, 101-110. [CrossRef]

41. Neese, F. The ORCA program system. WIREs Comput. Mol. Sci. 2012, 2, 73-78. [CrossRef]

42. Smith, W.; Forester, T.R. DL_POLY_2.0: A general-purpose parallel molecular dynamics simulation package. J. Mol. Graph. 1996, 14, 136-141. [CrossRef]

43. Kästner, J.; Carr, J.M.; Keal, T.W.; Thiel, W.; Wander, A.; Sherwood, P. DL-FIND: An open-source geometry optimizer for atomistic simulations. J. Phys. Chem. A 2009, 113, 11856-11865. [CrossRef] [PubMed]

44. Becke, A.D. Density-Functional Thermochemistry. III. The Role of Exact Exchange. J. Chem. Phys. 1993, 98, 5648-5652. [CrossRef]

45. Grimme, S.; Antony, J.; Ehrlich, S.; Krieg, H. A consistent and accurate ab initio parametrization of density functional dispersion correction (DFT-D) for the 94 elements H-Pu. J. Chem. Phys. 2010, 132, 154104. [CrossRef] [PubMed]

46. Weigend, F.; Ahlrichs, R. Balanced basis sets of split valence, triple zeta valence and quadruple zeta valence quality for $\mathrm{H}$ to Rn: Design and assessment of accuracy. Phys. Chem. Chem. Phys. 2005, 7, 3297-3305. [CrossRef] [PubMed]

Sample Availability: Samples of the compounds are not available from the authors.

(c) 2018 by the authors. Licensee MDPI, Basel, Switzerland. This article is an open access article distributed under the terms and conditions of the Creative Commons Attribution (CC BY) license (http://creativecommons.org/licenses/by/4.0/). 